\title{
Long-Term Depression of a Dopamine IPSC
}

\author{
Michael J. Beckstead and John T. Williams \\ Vollum Institute, Oregon Health and Science University, Portland, Oregon, 97239
}

Two determinants of dopamine release from terminals in striatal and limbic structures are the pattern and rate of dopamine neuron firing in the ventral midbrain. This activity is regulated in part by somatodendritic release of dopamine and subsequent feedback inhibition through activation of $\mathrm{D}_{2}$ receptors on dopamine neuron cell bodies and dendrites. This study describes stimulus-dependent long-term depression (LTD) of IPSCs mediated by dopamine. This LTD was blocked by chelation of postsynaptic intracellular calcium, was dependent on the activation of $\mathrm{D}_{2}$ receptors and was independent of glutamate-mediated transmission. Application of a high concentration of dopamine mimicked depression of the IPSC and prevented additional attempts to induce LTD, suggesting that the mechanism of the depression is agonist-dependent receptor activation. Using extracellular recording, there is an inhibition of firing that follows electrical stimulation, and after the induction of LTD the duration of that inhibition was decreased. Reduced inhibition could increase burst firing and action potential-dependent release of dopamine in terminal regions in vivo.

Key words: LTD; substantia nigra; VTA; plasticity; desensitization; GIRK

\section{Introduction}

Dopamine neurons in the ventral midbrain are important for initiation of movement, learning, and memory and contribute to the etiology of Parkinson's disease, schizophrenia, and drug abuse. Dopamine neuron firing communicates a signal in response to the presentation of an unexpected reward or associated conditioned stimulus (Schultz, 2002). This reinforces the behavioral processes that produced the reward, implicating dopamine in salience and incentive sensitization (Berridge and Robinson, 1998). Glutamate input from regions such as the prefrontal cortex stimulates midbrain dopamine neurons, promoting burst rather than single spike firing (Grace and Onn, 1989; Taber et al., 1995; Grillner and Mercuri, 2002; Floresco et al., 2003). Burst firing facilitates the supra-additive release of dopamine in terminal projection fields such as the olfactory tubercule and the nucleus accumbens. The resulting increase in extracellular dopamine overwhelms uptake transporters and produces the phasic response ultimately responsible for many of the behavioral consequences of dopamine release (Chergui et al., 1994; Floresco et al., 2003; Phillips et al., 2003).

Burst firing also facilitates dopamine release in somatodendritic regions of the midbrain (Bjorklund and Lindvall, 1975; Geffen et al., 1976; Kalivas and Duffy, 1991; Rice et al., 1997; Jaffe et al., 1998; Adell and Artigas, 2004), where dopamine neurons make dendrodendritic synapses onto other dopamine neurons (Wilson et al., 1977; Groves and Linder, 1983; Nirenberg et al., 1996). By using a combination of electrophysiological and genetic tools we recently identified an IPSC mediated by vesicular

Received July 28, 2006; revised Jan. 15, 2007; accepted Jan. 16, 2007

This work was supported by National Institute on Drug Abuse Grants F32 DA16467 (M.J.B.) and R01 DA4523 (J.T.W.). J.T.W. was a NARSAD Ritter Foundation Investigator.

Correspondence should be addressed to John T. Williams, Vollum Institute, L474, Oregon Health and Science University, 3181 Southwest Sam Jackson Park Road, Portland, OR 97239. E-mail: williamj@ohsu.edu. D0I:10.1523/JNEUROSCI.3251-06.2007

Copyright $\odot 2007$ Society for Neuroscience $\quad$ 0270-6474/07/272074-07\$15.00/0 dopamine release activating $\mathrm{D}_{2}$ dopamine autoreceptors in the ventral tegmental area (VTA) and substantia nigra (Beckstead et al., 2004, Ford et al., 2006). $\mathrm{D}_{2}$ receptor activation increases an inhibitory G-protein coupled inwardly rectifying potassium conductance (GIRK) that hyperpolarizes cells on a millisecond time scale and may contribute to the pause typically observed after a burst of action potentials (Lacey et al., 1987; Davila et al., 2003; Beckstead et al., 2004; Koyrakh et al., 2005). $\mathrm{D}_{2}$ dopamine receptor activation in the midbrain strongly inhibits dopamine cell firing (Pucak and Grace, 1994). Therefore, use-dependent plasticity of dopaminergic synapses could have important consequences for cell excitability, burst firing, terminal dopamine release, and dopamine-mediated behaviors.

The factors that affect synaptic strength have not been described for dopamine-mediated synaptic transmission. This study reports a long-term depression (LTD) of a G-protein coupled receptor-mediated IPSC resulting from dendritic release of dopamine in the ventral midbrain. The mechanism of this depression is through a postsynaptic desensitization of $\mathrm{D}_{2}$ autoreceptors.

\section{Materials and Methods}

All animal protocols were reviewed and approved by the Institutional Animal Care and Use Committee at Oregon Health and Science University. Dopamine, MK-801, DNQX, calmidazolium, staurosporine, prazosin, picrotoxin, cyclopiazonic acid, and L-glutamic acid were obtained from Sigma (St. Louis, MO). Baclofen, sulpiride, and hexamethonium were from Research Biochemicals International (Natick, MA). CGP 56999a was a gracious gift from Novartis Pharmaceuticals (Basel, Switzerland). LY 341495 and AM 251 were obtained from Tocris Bioscience (Ellisville, MO).

Brain slices were prepared from young adult [postnatal day 32 (P32)P95] male or female C57BL/6J mice (The Jackson Laboratory, Bar Harbor, ME) as described previously (Williams et al., 1984). Homozygous $(-/-) \beta$-arrestin 2 (arrestin 3 ) knock-out mice were used for one experiment (Kohout et al., 2001). Briefly, mice were placed in a chamber, anesthetized with halothane, and killed by decapitation. Brains were 
quickly removed and placed in a $0^{\circ} \mathrm{C}$ physiological solution (modified Krebs' buffer) containing the following (in $\mathrm{mM}$ ): $126 \mathrm{NaCl}, 2.5 \mathrm{KCl}, 1.2$ $\mathrm{MgCl}_{2}, 2.4 \mathrm{CaCl}_{2}, 1.4 \mathrm{NaH}_{2} \mathrm{PO}_{4}, 25 \mathrm{NaHCO}_{3}$, and 11 D-glucose. Horizontal slices of the ventral midbrain $(220 \mu \mathrm{m})$ were obtained and incubated for at least $25 \mathrm{~min}$ at $35^{\circ} \mathrm{C}$ in Krebs' containing MK-801 (10 $\left.\mu \mathrm{M}\right)$. Slices were placed in a recording chamber attached to an upright microscope (Carl Zeiss, Oberkochen, Germany) and maintained at $35^{\circ} \mathrm{C}$ with Krebs' solution perfused at a rate of $1.5 \mathrm{ml} / \mathrm{min}$. Infrared illumination was used to visualize dopamine cells in the substantia nigra pars compacta $(\sim 80 \%)$ and anterior lateral VTA $(\sim 20 \%)$, which were identified by visual inspection of their location in relation to the midline, the third cranial nerve, and the medial terminal nucleus of the accessory optic tract. Physiological identification was based on the presence of spontaneous pacemaker firing of wide ( $\sim 2 \mathrm{~ms})$ action potentials at $1-5 \mathrm{~Hz}$, a large hyperpolarization-induced $\mathrm{I}_{\mathrm{H}}$ current, and sensitivity to an iontophoretic application of dopamine. Whole-cell patch-clamp recordings were obtained with large glass electrodes (1.5-2.0 M $\Omega$; World Precision Instruments, Sarasota, FL) and an internal pipette solution containing the following (in mM): $115 \mathrm{~K}$-methylsulfate, $20 \mathrm{NaCl}, 1.5 \mathrm{MgCl}_{2}, 2 \mathrm{ATP}$, 0.2 GTP, 10 phosphocreatine, and either 10 BAPTA, 1 EGTA, 0.1-0.4 EGTA, or 0.4 Fluo-4, pH 7.30-7.35, 270-280 mOsm. Cells were voltage clamped at $-60 \mathrm{mV}$ with an Axopatch 1D amplifier (Molecular Devices, Foster City, CA) to prevent spontaneous cell firing. Series resistance was monitored to insure sufficient and stable electrical access $(<7 \mathrm{M} \Omega)$ to the inside of the cell was maintained. Drugs were applied by bath perfusion, and dopamine was also applied iontophoretically. Iontophoretic pipettes were pulled from thin-wall glass microelectrodes (resistance 100-150 $\mathrm{M} \Omega$ ) filled with dopamine ( $1 \mathrm{M}$ ) and placed with the tip within $10 \mu \mathrm{m}$ of the soma. Leakage was prevented by application of a negative backing current $(1.0-5.0 \mathrm{nA})$ and dopamine was ejected as a cation with application of $+10-190 \mathrm{nA}$ for 1-5 s with an Axoclamp 2A amplifier (Molecular Devices). This brief, high dopamine concentration produced a maximal $\mathrm{D}_{2}$ receptor-mediated current that recovered rapidly ( $\left.<3 \mathrm{~min}\right)$.

The $\mathrm{D}_{2}$ receptor-mediated IPSC was obtained as described previously (Beckstead et al., 2004) in the presence of receptor blockers picrotoxin $(100 \mu \mathrm{M})$, prazosin (100 nM), MK-801 (10 $\mu \mathrm{M})$, CGP 56999a (100 nM), and in some experiments DNQX $(10 \mu \mathrm{M})$, hexamethonium $(50 \mu \mathrm{M})$, or LY $341495(100 \mu \mathrm{M})$. A bipolar platinum stimulating electrode was placed into the slice 50-200 $\mu \mathrm{M}$ caudal to the cell and IPSCs were evoked by electrically applying a train of five action potentials at $40 \mathrm{~Hz}$ once every $50-100 \mathrm{~s}$. The CB1 cannabinoid receptor antagonist AM $251(1 \mu \mathrm{M})$ was added for the $\mathrm{GABA}_{\mathrm{B}}$ synaptic experiment to inhibit retrograde endocannabinoid inhibition of GABA terminal release, as well as sulpiride (50-200 nM) to block $\mathrm{D}_{2}$ dopamine receptor signaling.

For the cell-firing experiment, dopamine neurons were loosely patched with slightly higher resistance electrodes (2-3 M $\Omega$ ) using a modified Krebs' internal solution. Externally, the bath solution contained picrotoxin $(100 \mu \mathrm{M})$, prazosin (100 nM), MK-801 (10 $\mu \mathrm{M})$, CGP 56999a (100 nM), DNQX (10 $\mu \mathrm{M})$, and hexamethonium (50 $\mu \mathrm{M})$. Neurons that exhibited spontaneous firing in a pacemaker pattern were maintained in the cell-attached patch configuration for the duration of the experiment. Often ( $\sim 50 \%$ of the time) the loose patch began to break into the neuron (whole cell) before the end of the experiment, evidenced by visual identification of an afterhyperpolarization potential and an increase in spontaneous firing rate. In these cases, the experiment was immediately terminated.

For the calcium-imaging experiment, the recording electrode was filled with Fluo-4 $(40 \mu \mathrm{M})$ and no other calcium chelators. Changes in intracellular calcium concentrations were determined by monitoring real-time fluorescence with a confocal microscope imaging system (Solamere Technology, Salt Lake City, UT).

Data was collected on a Macintosh (Apple, Sunnyvale, CA) G4 computer using Axograph 4.5.1 (Molecular Devices) and Chart 4.0.1 (Molecular Devices), and stored for offline analysis at a later time. One- and two-way ANOVA was used to assess effects of independent variables, followed when appropriate by Tukey's (all comparisons) or Dunnett's (versus a control) post hoc test. When only two groups were involved, comparisons were made with paired (within cells) and unpaired $t$ tests. Statistical significance was defined a priori with $\alpha=0.05$. Data are pre-

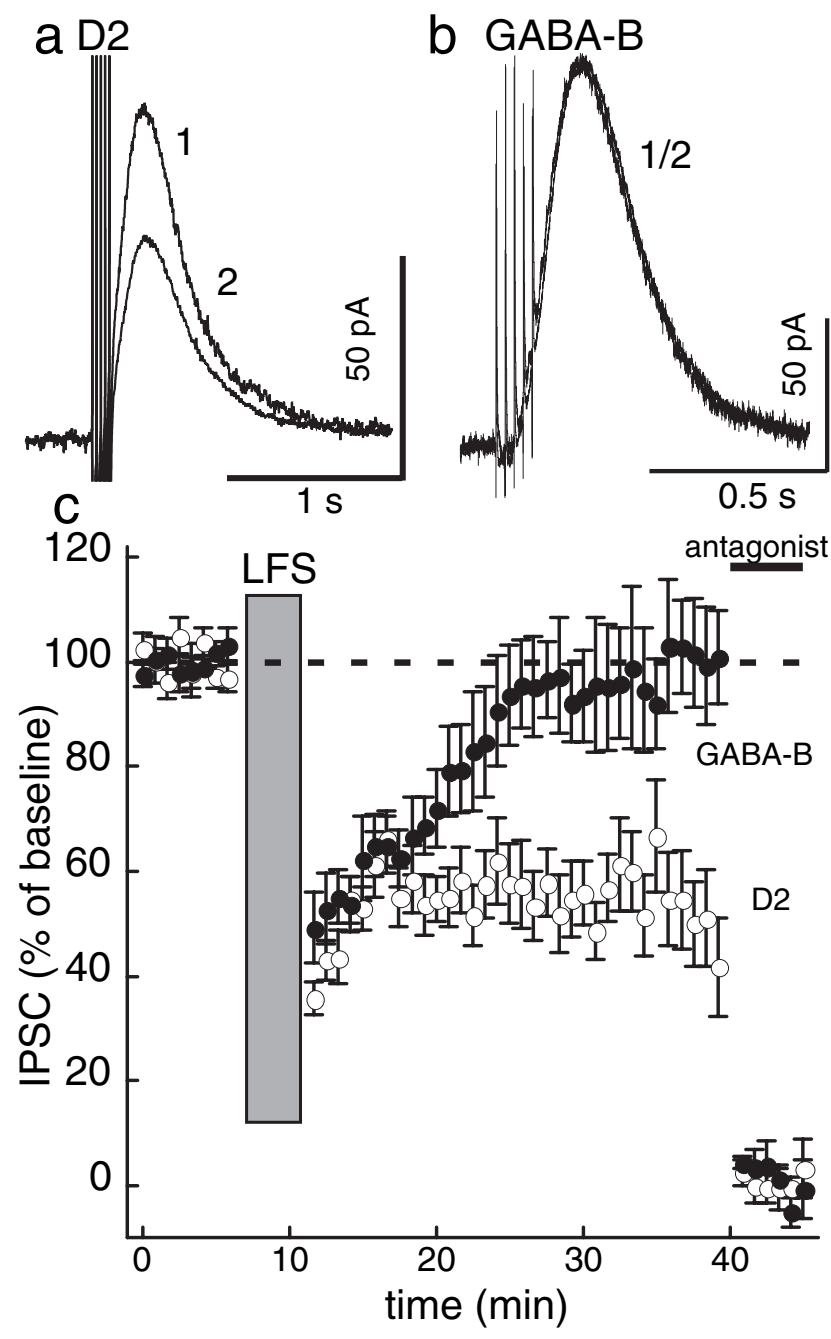

Figure 1. Low-frequency stimulation induces LTD of dopamine but not GABA $\mathrm{IPSCS}, \boldsymbol{a}$, Low-frequency stimulation (LFS, $0.5 \mathrm{~ms}, 2 \mathrm{~Hz}$ for $300 \mathrm{~s}$ ) induced depression of dopamine IPSCs (1, pre-LFS; 2 , post-LFS; $n=13)$. $\boldsymbol{b}$, In contrast, low-frequency stimulation produced temporary depression but failed to induce LTD of GABA ${ }_{B}$ receptor-mediated IPSCS (1, pre-LFS; 2 , post-LFS; $n=5 ; p=0.0005)$. $c$, Depression of the dopamine IPSC persisted for the length of the experiment (c), and administration of the antagonist (GP 56999a (100 nM) or sulpiride $(50-200 \mathrm{~nm})$ confirmed that the IPSCS were mediated by $\mathrm{GABA}_{B}$ or $\mathrm{D}_{2}$ receptors, respectively.

sented as mean \pm SE with $n$ designating the number of cells obtained in each experimental group.

\section{Results}

Long-term depression of $\mathrm{D}_{2}$ - but not $\mathrm{GABA}_{B}$ receptor-mediated IPSCs

The recent identification of a synaptic potential mediated by dopamine (Beckstead et al., 2004) made possible an examination of stimulation-induced synaptic changes that could be important for adaptations observed in vivo. Whole-cell recordings were obtained from dopamine neurons in the lateral VTA (20\%) or substantia nigra pars compacta $(80 \%)$ in horizontal slices of the mouse ventral midbrain. A bipolar platinum stimulating electrode was placed 50-200 $\mu \mathrm{m}$ caudal to the dopamine neuron and used to evoke dendrodendritic dopamine IPSCs. Using a control intracellular solution that contained EGTA (0.4 mM), lowfrequency electrical stimulation $(0.5 \mathrm{~ms}, 2 \mathrm{~Hz}$ for $300 \mathrm{~s})$ induced a robust LTD of the dopamine IPSC (Fig. 1a,c) in 12 of 13 neurons tested. No recovery from LTD was ever observed (up to 60 min after the low-frequency stimulation). 
$\mathrm{GABA}_{\mathrm{B}}$ receptors activate the same GIRK conductance in dopamine neurons as $\mathrm{D}_{2}$ receptors (Lacey et al., 1988; Davila et al., 2003; Beckstead et al., 2004; Koyrakh et al., 2005). Thus, the receptor specificity of the LTD was next tested by examination of $\mathrm{GABA}_{\mathrm{B}}$ receptor-mediated IPSCs. Low frequency stimulation $(0.5 \mathrm{~ms}, 2 \mathrm{~Hz}$ for $300 \mathrm{~s})$ decreased the $\mathrm{GABA}_{\mathrm{B}}$ IPSC, an effect that recovered completely within 15-20 min (Fig. 1b). It is unclear whether this short-term synaptic depression was presynaptic or postsynaptic, but the duration of the inhibition did not resemble LTD of $\mathrm{D}_{2}$ receptor IPSCs (Fig. 1c). This indicates a distinct difference between plasticity of $\mathrm{D}_{2}$ and $\mathrm{GABA}_{\mathrm{B}}$ receptor synapses and suggests that all GIRK conductances are not susceptible to long-term depression subsequent to this stimulation protocol.

\section{Depression of the dopamine IPSC is blocked with strong} calcium chelation

The induction of LTD at glutamate synapses is dependent on a rise in intracellular calcium that can often result from the activation of NMDA or metabotropic glutamate receptors (mGluRs) (Malenka and Bear, 2004). This was not the case in the present study as NMDA receptors were blocked during the LTD experiments (with MK-801, $10 \mu \mathrm{M}$ ). Similarly the AMPA receptor blocker DNQX $(10 \mu \mathrm{M})$ and the nicotinic acetylcholine receptor antagonist hexamethonium $(50 \mu \mathrm{M})$ did not prevent depression of the dopamine IPSC $(n=13$, LTD $-41.8 \pm 4.0 \%$ change) (data not shown). Thus, calcium entry through these ionotropic receptor channels is not necessary to induce LTD.

To determine the role of intracellular calcium in the depression of the dopamine IPSC, low-frequency stimulation was applied in the presence of different levels of intracellular calcium chelation. The induction of LTD was blocked when intracellular calcium was chelated to very low concentrations using an internal solution with BAPTA (10 mM and no added $\mathrm{Ca}^{2+}$ ) (Fig. 2a,b). A small amount of LTD was observed after low frequency stimulation using an internal containing EGTA ( $1 \mathrm{~mm}$ and no added $\mathrm{Ca}^{2+}$ ) (Fig. 2b).

Activation of mGluRs can increase intracellular calcium, resulting in the induction of plasticity at glutamate synapses onto dopamine neurons (Bellone and Luscher, 2005). To determine whether mGluR activation was necessary for depression of dopaminergic synapses, experiments were conducted in the presence of the mGluR antagonist LY $341495(100 \mu \mathrm{M})$. LTD was not inhibited by mGluR antagonism, nor when intracellular calcium stores were depleted with cyclopiazonic acid (10 $\mu \mathrm{M})$ (Fig. $2 c$ ). This suggests that LTD of the dopamine IPSC was not caused by a rise in internal calcium resulting from release from intracellular stores or from calcium entry secondary to mGluR activation. LTD was also not induced by perfusion with a high concentration of glutamate ( $1 \mathrm{mM}$; change from baseline, $-1.7 \pm 4.6 \% ; n=5$ ) (data not shown) in the absence of AMPA and mGluR blockers. This result confirms that AMPA and mGlu receptor activation are not involved in depression of the dopamine IPSC. Finally, LTD was not induced by a series of postsynaptic depolarizations (to $0 \mathrm{mV}$ for $10 \mathrm{~ms}, 2 \mathrm{~Hz}$ for $300 \mathrm{~s}$; change from baseline, $+7.0 \pm$ $8.6 \% ; n=7$ ) (data not shown). This suggests that unlike LTD at glutamate synapses on dopamine neurons (Jones et al., 2000; Thomas et al., 2000), LTD of the dopamine IPSC cannot be reproduced by a depolarization-induced influx of calcium through voltage-gated channels. Together, the results suggest that depression of the dopamine IPSC is dependent on a physiological level of calcium and not dependent on a transient rise in intracellular calcium.

There was no change in the amplitude of the current induced
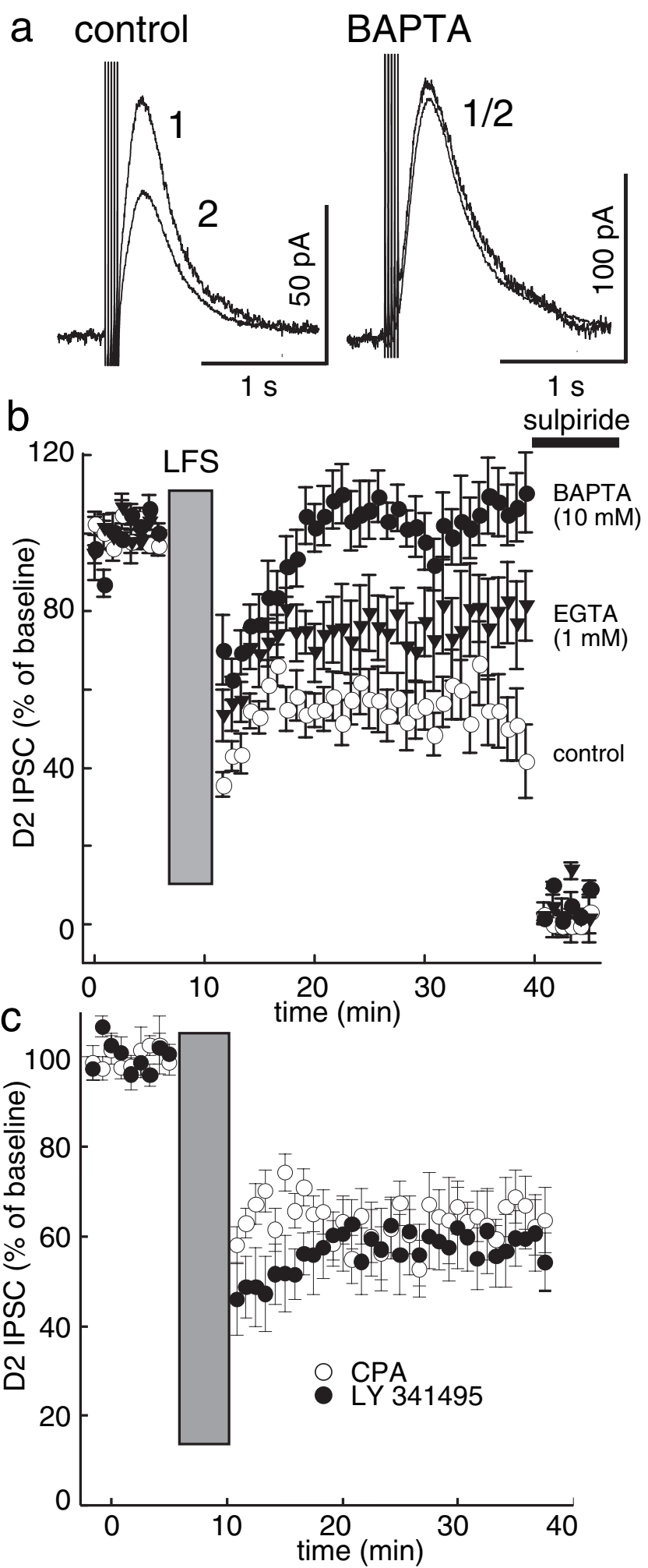

Figure 2. LTD of the dopamine IPSC is blocked by chelating intracellular calcium. $\boldsymbol{a}, \boldsymbol{b}$, Strongly chelating intracellular calcium with BAPTA $(10 \mathrm{~mm})$ prevented induction of LTD $(\boldsymbol{a} ; 1$, pre-LFS; 2 , post-LFS), and mildly chelating intracellular calcium with EGTA (1 $\mathrm{mm}$ ) reduced the amplitude of the synaptic depression (b). Sulpiride ( $50-200 \mathrm{~nm}$ ) was used to confirm that the IPSCs were mediated by $D_{2}$ receptors. Dunnett's test indicated a nonsignificant difference from control conditions for EGTA (1 mM; $p=0.068)$ and a significant difference from control conditions for BAPTA (10 mm; $p=0.00002) . n=8-13$ in each group. $c$, LTD induction was maintained in the presence of the mGluR antagonist LY $341495(100 \mu \mathrm{m}, n=6)$ or after depletion of intracellular calcium stores with cyclopiazonic acid (CPA) $(10 \mu \mathrm{m} ; n=6)$. 

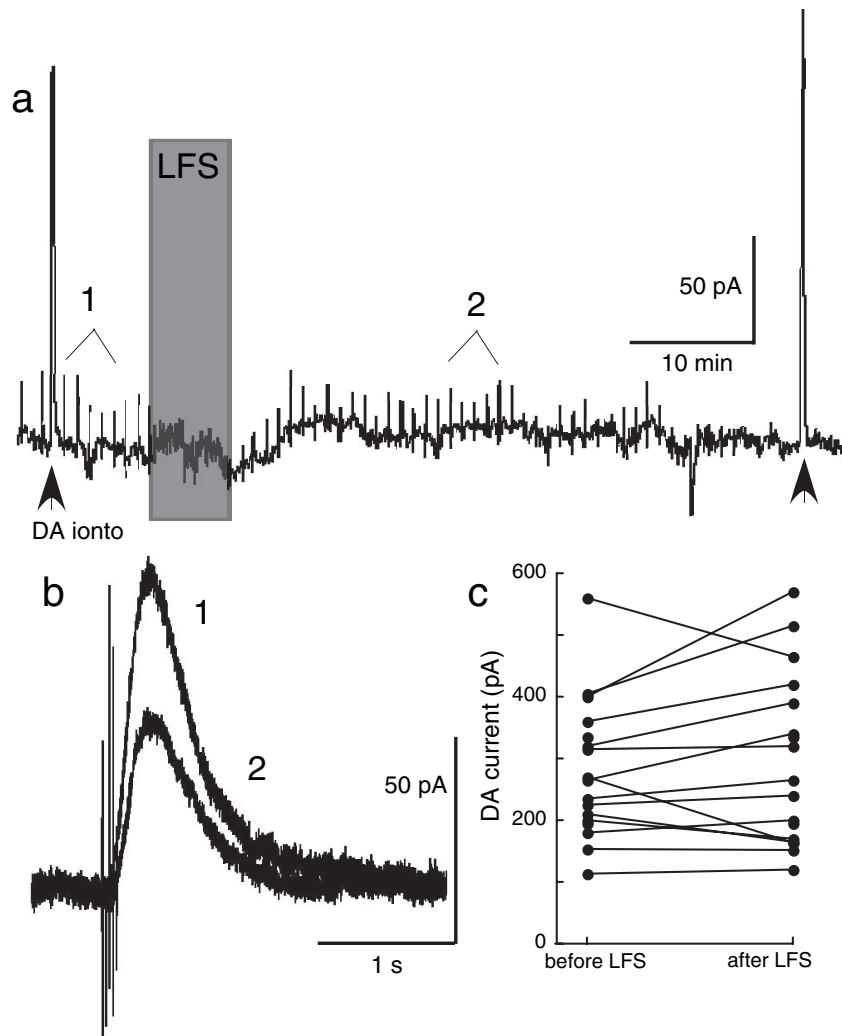

Figure 3. Low-frequency stimulation does not affect currents elicited by exogenous dopamine. $\boldsymbol{a}$, One of the tests used to confirm that neurons being recorded were dopaminergic (see Materials and Methods) was a brief application of exogenous dopamine delivered via an iontophoretic pipette at the beginning of each recording (DA ionto arrowhead). In some neurons, a second iontophoretic pulse was applied at the end of the experiment (second arrowhead) to assess changes in maximum dopamine current. $\boldsymbol{b}$, This sample trace is from a neuron that expressed LTD (1, before LFS; 2 , after LFS). $\boldsymbol{c}$, There was no consistent change in the iontophoretic current throughout the course of these experiments (average $+4.7 \pm 4.9 \% ; n=17$ ).

by iontophoretic application of dopamine measured before and after LTD (Fig. 3). Although the location of dopamine release sites is not known, a dendritic site is more likely than somatic areas. Iontophoretic application of dopamine was focused at the cell body, so the current evoked by synaptic release and iontophoretic application of dopamine may result from the activation of different populations of $\mathrm{D}_{2}$-receptors. The observation that synaptic current was depressed after the LTD protocol whereas the current induced by iontophoretic application of dopamine was unaffected also suggests a segregation of receptors that were activated by synaptic and iontophoretic application of dopamine.

\section{$D_{2}$ receptor desensitization is decreased by strong calcium chelation}

One potential mechanism that would result in a receptor-specific inhibition of the dopamine IPSC is through desensitization of the receptors responsible for the IPSC. To test this possibility, a high concentration of dopamine $(100 \mu \mathrm{M})$ was bath applied and the subsequent outward current was measured with control internal solution (EGTA, $0.4 \mathrm{~mm}$ ) and with an internal solution containing BAPTA (10 mM) (Fig. 4 supplemental Fig. 4, available at www.jneurosci.org as supplemental material). One striking difference between the two internal solutions was the amplitude of the outward current induced by dopamine was larger with the BAPTA internal. Larger amplitude currents were observed when dopamine was applied via bath perfusion (control $191 \pm 26 \mathrm{pA}$;

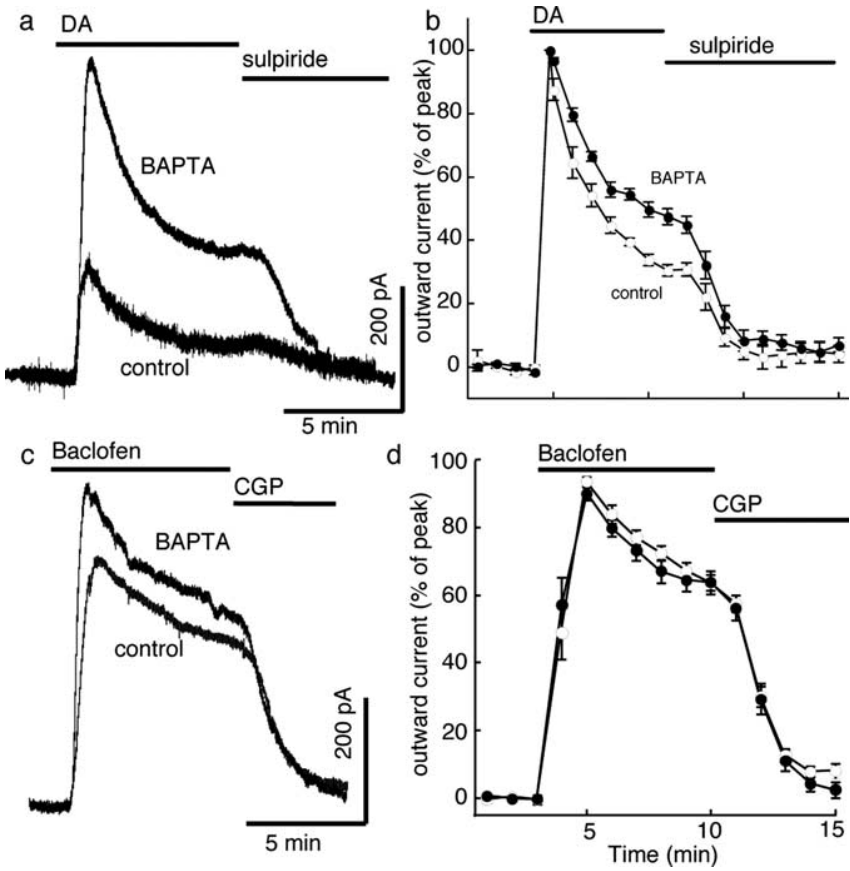

Figure 4. Chelating calcium increases the amplitude of GIRK currents and decreases the desensitization rate of $D_{2}$ receptor-mediated currents. $\boldsymbol{a}, \boldsymbol{b}$, When intracellular calcium was chelated with BAPTA $(10 \mathrm{~mm})$, bath perfusion of dopamine (DA; $100 \mu \mathrm{M})$ elicited larger $\mathrm{D}_{2}$ receptor-mediated outward currents $(\boldsymbol{a})$ that desensitized less $\left(\boldsymbol{a}, \boldsymbol{b} ; \boldsymbol{p}=0.00093 ; F_{(9,144)}=\right.$ 3.35 for time-chelation interaction; $n=8-10) . \boldsymbol{c}, \boldsymbol{d}, \mathrm{GABA}_{\mathrm{B}}$ receptor-mediated outward currents elicited by baclofen $(30 \mu \mathrm{M})$ were also larger in the presence of calcium chelation $\left(t_{(40)}=\right.$ $2.52 ; p=0.016 ; n=18-24)$, but there was no difference in desensitization rate $(\boldsymbol{c}, \boldsymbol{d} ; p=$ 0.507 for time-chelator interaction; $\left.F_{(6,168)}=0.884 ; n=13-17\right)$. Perfusion of (GP 56999a $(100 \mathrm{~nm})$ or sulpiride $(50-200 \mathrm{~nm})$ confirmed that the currents were mediated by $\mathrm{GABA}_{B}$ or $\mathrm{D}_{2}$ receptors, respectively.

BAPTA $294 \pm 22$ pA; $n=20-21$ ) (Fig. 4a) (data not shown), iontophoresis (control $249 \pm 19$; BAPTA $413 \pm 34$ pA; $n=25$ ), and synaptic release (control $56.6 \pm 5.4$ pA; BAPTA $80.2 \pm 7.3$ pA; $n=15-19$ ) (Fig. 2a). The second observation was that the $\mathrm{D}_{2}$ receptor-dependent outward currents desensitized more slowly and less completely with the BAPTA-containing internal than with control internal (Fig. $4 a, b$ ). The results of both of these experiments have also been reproduced in dopamine neurons from Wistar rats (peak currents, BAPTA $211 \pm 28 \mathrm{pA}$, control $116 \pm 12 \mathrm{pA}, p=0.005 ; 5$ min desensitization, BAPTA $36.0 \pm$ $2.6 \%$, control $63.8 \pm 5.2 \%, p=0.0001 ; n=12-13$ ).

The receptor specificity of desensitization was examined by the activation of $\mathrm{GABA}_{\mathrm{B}}$ receptors with baclofen $(30 \mu \mathrm{M})$. The peak amplitude of the current induced by baclofen was significantly larger with the BAPTA-containing internal (control $309 \pm$ 27 pA; BAPTA $439 \pm 48$ pA; $n=18-24$ ) (data not shown), but there was no difference in the extent of desensitization during a 7 min application of baclofen (Fig. $4 c, d$ ). Therefore, although chelating calcium with a high concentration of BAPTA increased the GIRK-mediated peak current, desensitization and the induction of LTD were $\mathrm{D}_{2}$ receptor-specific.

\section{Desensitization of $\mathrm{D}_{2}$ receptors and LTD}

To test whether $\mathrm{D}_{2}$ receptor activation and subsequent desensitization was responsible for depression of the dopamine IPSC, a high concentration of dopamine $(100 \mu \mathrm{M})$ was bath applied. The high concentration of dopamine reliably occluded the IPSC during the superfusion and for several minutes as the dopamine washed out of the slice (Fig. 5). With BAPTA-containing internal 
solution, the amplitude of the IPSC returned to baseline 20-30 min after washing the dopamine (Fig. $5 c, d$ ). In experiments with the control internal solution (EGTA, $0.4 \mathrm{~mm}$ ) the IPSC remained depressed (Fig. 5). Furthermore, in slices that had already been treated with a desensitizing concentration of dopamine, lowfrequency stimulation did not induce a decrease in the IPSC. That is, previous desensitization with dopamine occluded LTD (supplemental Fig. 3, available at www.jneurosci.org as supplemental material). This suggests that bath application of a high concentration of dopamine activated and desensitized dendritic and somatic $\mathrm{D}_{2}$ receptors, resulting in a depression of the dopamine IPSC.

Imaging of intracellular calcium was used to further investigate the synergism between $\mathrm{D}_{2}$ receptor desensitization and resting calcium required for LTD. Cells were loaded with Fluo-4 (40 $\mu \mathrm{M})$ without other calcium chelators. As expected, depolarization of the neuron (to $0 \mathrm{mV}$ for $50-500 \mathrm{~ms}$ ) resulted in a dramatic rise in intracellular calcium, whereas iontophoresis of dopamine had no effect on calcium levels (supplemental Fig. 1, available at www.jneurosci.org as supplemental material). Application of the lowfrequency stimulation protocol had no obvious effect on calcium levels. Furthermore, neither the outward current nor the rise in calcium resulting from the depolarization were changed by induction and expression of LTD (supplemental Fig. 2, available at www.jneurosci.org as supplemental material). Thus, it appears that a change in intracellular calcium is not responsible for LTD of the dopamine IPSC. Rather, resting calcium levels and the activation of $\mathrm{D}_{2}$ receptors is sufficient (and necessary) to induce LTD.

If desensitization is responsible for LTD of the dopamine IPSC, then any manipulation that inhibits calcium-dependent desensitization of $\mathrm{D}_{2}$ receptors should also inhibit the induction of LTD. Calmodulin, PKC, and $\beta$-arrestin are three potential mediators of $\mathrm{D}_{2}$ receptor signaling (Bofill-Cardona et al., 2000; Gainetdinov et al., 2004; Namkung and Sibley, 2004) that were next tested for their role in desensitization. Inhibiting calmodulin with calmidazolium $(4 \mu \mathrm{M})$ or PKC with staurosporine $(1 \mu \mathrm{M})$ had no effect on the desensitization induced by dopamine (100 $\mu \mathrm{M}$ ) applied for $7 \mathrm{~min}$ (control, $69.4 \pm 1.8 \%$; calmidazolium, $71.0 \pm 3.3 \%$; staurosporine, $69.1 \pm 4.9 \% ; n=6-8$ ). Desensitization was also unchanged in recordings from $\beta$-arrestin 2 knock-out mice $(72.9 \pm 2.4 \% ; n=7)$, and LTD of the dopamine IPSC was successfully induced by low-frequency stimulation in four of five cells tested from these animals (data not shown). This suggests that none of these three mediators is singly responsible for $\mathrm{D}_{2}$ receptor desensitization or LTD. The mechanism(s) that underlie this desensitization remain unknown.

\section{Depression of the dopamine IPSC decreases the stimulus-induced pause}

The firing of dopamine neurons was examined in the cellattached patch configuration to determine whether depression of the dopamine IPSC could affect the firing rate and/or pattern. The spontaneous firing of dopamine cells in brain slices is invari- ably a rhythmic, pacemaker pattern. Applying a train of five stimulations $(0.5 \mathrm{~ms}, 40 \mathrm{~Hz})$ produced a pause in firing that was $\mathrm{D}_{2}$ receptor-dependent and lasted for $\sim$ one second (Beckstead et al., 2004). After the application of the low-frequency stimulation protocol used to induce LTD, there was a modest decrease in the duration the $\mathrm{D}_{2}$ receptor-mediated pause in eight of eight cells tested (Fig. 6). There was no effect on the spontaneous pacemaker firing rate $(+4.9 \pm 2.1 \% ; n=8)$ (data not shown). This result demonstrates that stimulation-induced depression of the dopamine IPSC can affect the pattern of firing after a burst of activity without changing the basal firing rate.

\section{Discussion}

The results demonstrate that low-frequency electrical stimulation produces a robust and persistent decrease in transmission at dendrodendritic dopamine synapses. The blockade of LTD with intracellular application of a high concentration of BAPTA suggests a postsynaptic site of action. This intracellular solution also increased GIRK-dependent currents and reduced $\mathrm{D}_{2}$-receptor dependent desensitization. Thus, it appears that desensitization of $\mathrm{D}_{2}$ receptors may underlie LTD. Another way that is commonly used to identify the site of action is with a paired-pulse protocol. Although the paired-pulse ratio was not affected after the induction of LTD, which would suggest a postsynaptic change, it was considered to be a very insensitive measure because it was not changed even by experiments where presynaptic release was drastically decreased (our unpublished observation).

Although the IPSC is thought to result from dendrodendritic release of dopamine, several observations indicate that the IPSC is not the result of dopamine released from the neuron that is being recorded. (1) All experiments were done in voltage clamp making it unlikely that there would be sufficient calcium entry during the stimulus to evoke transmitter release. (2) There is no change in the outward current after a depolarization following the induction of LTD (supplemental Fig. 2, top traces, available at www.jneurosci.org as supplemental material). (3) Depolarizing the postsynaptic neuron repeatedly to $0 \mathrm{mV}$ at $2 \mathrm{~Hz}$ for $300 \mathrm{~s}$ did 


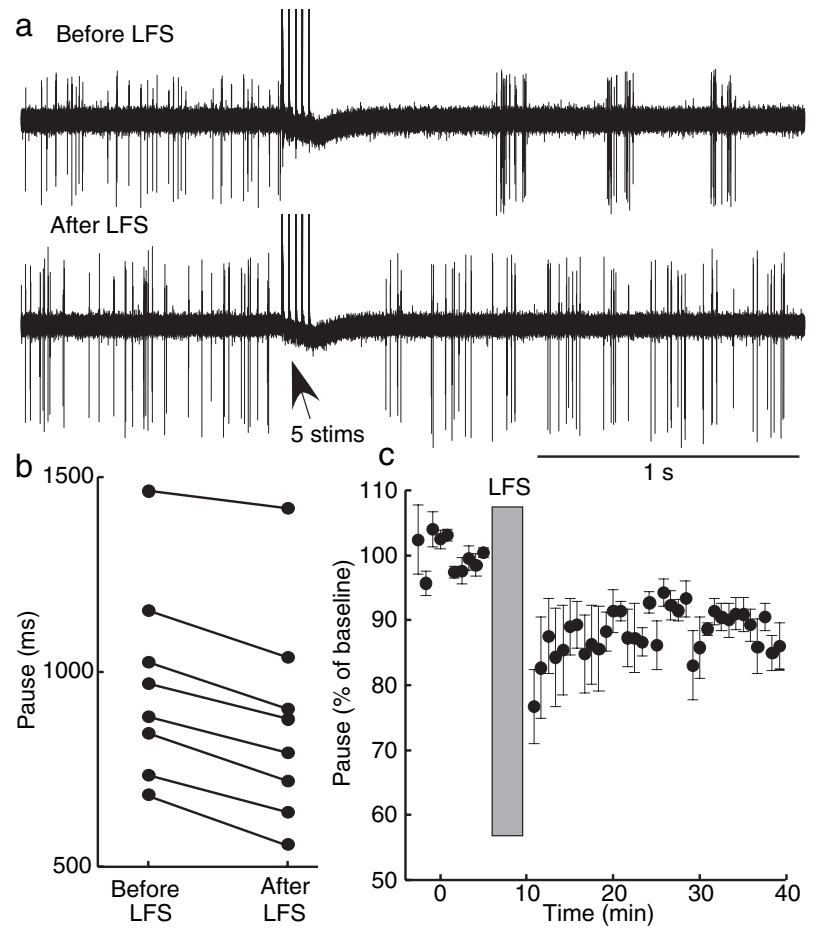

Figure 6. LTD of the dopamine IPSC increases neuron firing. Recordings were obtained in the loose cell-attached patch configuration, and the pacemaker firing pattern that dopamine neurons exhibit in vitro was analyzed. $\boldsymbol{a}$, As reported previously (Beckstead et al., 2004), electrical stimulation (5 stims) produced a pause in firing that lasted $\sim 1 \mathrm{~s}$, a result of $\mathrm{D}_{2}$ receptor activation (top trace, 13 sweeps overlaid). $\boldsymbol{b}$, Low-frequency stimulation $(0.5 \mathrm{~ms}, 2 \mathrm{~Hz}, 300 \mathrm{~s}$ ) shortened the duration of the pause ( $\boldsymbol{a}$, bottom trace, 13 sweeps overlaid) in eight of eight cells tested $\left(\boldsymbol{b} ; t_{(8)}=5.92 ; p=0.0004\right)$. $\boldsymbol{c}$, This change in firing produced by synaptic depression did not recover for the duration of the experiment.

not decrease in the IPSC either by causing an increase in intracellular calcium or by evoking dopamine release. (4) The release of dopamine from a cell filled with BAPTA $(10 \mathrm{~mm})$ should be blocked from the chelation of calcium. Larger IPSCs were observed with the BAPTA internal solution. Together, these results indicate that there was insufficient dopamine release from the postsynaptic neuron to affect the IPSC.

\section{Long-term synaptic depression}

LTD is often described experimentally as a persistent decrease in synaptic strength that occurs in response to low-frequency electrical stimulation (1-5 Hz, 5-15 min). It has been demonstrated extensively at glutamate synapses (Malenka and Bear, 2004), a few central $\mathrm{GABA}_{\mathrm{A}}$ and glycinergic synapses (Gaiarsa et al., 2002) and at a kainate synapse in the perirhinal cortex (Park et al., 2006). The depression of dopamine IPSCs described here was blocked by buffering intracellular calcium to a very low level with BAPTA, indicating that LTD is mediated by a postsynaptic mechanism. Unlike some forms of LTD, the depression of the dopamine IPSC does not require a rise in intracellular calcium (Malenka and Bear, 2004). The LTD observed in the present study is similar to that described at excitatory AMPA receptordependent synapses on dopamine neurons, where LTD is blocked by chelating intracellular calcium and is not NMDA receptor-dependent (Jones et al., 2000; Thomas et al., 2000; Thomas and Malenka, 2003). A recent report suggests that mGluR activation depresses excitatory transmission in the VTA in a manner distinct from low-frequency stimulation-induced LTD (Bellone and Luscher, 2005). Regardless of mechanistic dif- ferences, the present findings demonstrate that dopamine synapses can undergo use-dependent decreases in synaptic strength in a manner similar to previously reported forms of synaptic plasticity. A comparison to other forms of LTD at $\mathrm{G}_{\mathrm{i} / \mathrm{o}}$-coupled inhibitory synapses is not possible, as no others have been reported.

LTD was induced by prolonged activation of $\mathrm{D}_{2}$ receptors, either by evoking synaptic release of endogenous dopamine or by perfusion of a high concentration of dopamine. Simply increasing intracellular calcium with glutamate receptor activation or repeated depolarizations did not induce LTD. Furthermore, activation of $\mathrm{D}_{2}$ receptors when intracellular calcium was lowered with BAPTA also did not induce LTD. Thus, induction of LTD required cooperation between a resting calcium level and $\mathrm{D}_{2}$ receptor desensitization. The calcium-imaging experiments confirmed that a rise in intracellular calcium was not required for depression of the dopamine IPSC.

\section{$D_{2}$ receptor-dependent desensitization}

Desensitization of G-protein coupled receptors has been extensively studied in neurons and is thought to involve phosphorylation by G-protein-coupled receptor kinases and subsequent binding of $\beta$-arrestin (for review, see Gainetdinov et al., 2004). This desensitization mechanism is well established and explains many of the pharmacological effects of exogenous compounds on G-protein-coupled receptor signaling in central neurons. The demonstration of a decreasing response of photoreceptors to a prolonged exposure to light suggests a physiological role for desensitization of G-protein-coupled receptors (Calvert and Makino, 2002). The present work expands this evidence by demonstrating that G-protein-coupled receptor desensitization can produce synaptic plasticity and cause a robust physiological adaptation in response to the release of endogenous dopamine. Repetitive release of dopamine in dendritic areas may produce a transient high local concentration of dopamine at postsynaptic receptors resulting in desensitization. The localized action of endogenous dopamine was demonstrated by experiments showing that low-frequency stimulation did not decrease the current elicited by dopamine applied at the soma by iontophoresis. This suggests that different receptors may mediate the local action of vesicular dopamine and the exogenously applied dopamine. Desensitization of synaptically activated receptors produced depression of the IPSC whereas receptors that were activated by the iontophoretic application of dopamine applied at the cell body remained unaffected.

Inhibitory autoreceptors such as the $\mathrm{D}_{2}$ receptor are thought to provide a negative cellular feedback mechanism. The depression of the dopamine IPSC would diminish autoreceptor signaling in dopamine neurons, effectively removing one mechanism that "brakes" cell excitability. Thus, autoreceptor desensitization is itself counterintuitive and seems more likely to be responsible for the creation of disease states rather than serving a homeostatic physiological role. Autoreceptor desensitization in the cell body region could also be responsible for some of the effects of the dopamine precursor L-DOPA in Parkinson's disease and other hypodopaminergic syndromes. If L-DOPA also induced sustained depression of $\mathrm{D}_{2}$ receptors in the substantia nigra, it could directly increase cell excitability and firing. This would increase terminal dopamine release and perhaps contribute to therapeutic efficacy. 


\section{LTD increases dopamine neuron firing}

In vivo, dopamine neurons switch between a single pulse, random firing pattern and a more active bursting mode consisting of series of 2-8 closely spaced action potentials (Grace and Bunney, 1984). Bursting facilitates release of dopamine in terminal limbic fields, overwhelming uptake transporters and producing a supraadditive phasic response (Chergui et al., 1994; Floresco et al., 2003). This transition from tonic to phasic levels of extracellular dopamine is hypothesized to be ultimately responsible for many of the behavioral consequences of dopamine release (Phillips et al., 2003). The excitatory and inhibitory inputs that shape the pattern of activity are severed in acutely prepared brain slices and, consequently, dopamine neurons exhibit a rhythmic, pacemaker-like spontaneous firing pattern in vitro (Grace and Onn, 1989). The low-frequency stimulation-induced depression of the dopamine IPSC did not significantly increase the dopamine neuron pacemaker firing rate. However, when a burst of action potentials was mimicked with a train of five stimulations, the duration of the postburst pause was decreased. Although it is difficult to predict the precise influence on firing in vivo, these results suggests that plasticity of the dopamine IPSC would more prominently affect active bursting cells than quiescent or slowly firing ones.

In summary, applying low-frequency stimulation to dopamine neurons in the ventral midbrain induces a novel form of synaptic plasticity: long-term depression of dendrodendritic dopamine-mediated IPSCs. The mechanism for this plasticity is a calcium-dependent, agonist-induced postsynaptic desensitization of $\mathrm{D}_{2}$ receptors.

\section{References}

Adell A, Artigas F (2004) The somatodendritic release of dopamine in the ventral tegmental area and its regulation by afferent transmitter systems. Neurosci Biobehav Rev 28:415-431.

Beckstead MJ, Grandy DK, Wickman K, Williams JT (2004) Vesicular dopamine release elicits an inhibitory postsynaptic current in midbrain dopamine neurons. Neuron 42:939-946.

Bellone C, Luscher C (2005) mGluRs induce a long-term depression in the ventral tegmental area that involves a switch of the subunit composition of AMPA receptors. Eur J Neurosci 21:1280-1288.

Berridge KC, Robinson TE (1998) What is the role of dopamine in reward: hedonic impact, reward learning, or incentive salience? Brain Res Brain Res Rev 28:309-369.

Bjorklund A, Lindvall O (1975) Dopamine in dendrites of substantia nigra neurons: suggestions for a role in dendritic terminals. Brain Res 83:531-537.

Bofill-Cardona E, Kudlacek O, Yang Q, Ahorn H, Freissmuth M, Nanoff C (2000) Binding of calmodulin to the D2-dopamine receptor reduces receptor signaling by arresting the $\mathrm{G}$ protein activation switch. J Biol Chem 275:32672-32680.

Calvert PD, Makino CL (2002) The time course of light adaptation in vertebrate retinal rods. Adv Exp Med Biol 514:37-60.

Chergui K, Suaud-Chagny MF, Gonon F (1994) Nonlinear relationship between impulse flow, dopamine release and dopamine elimination in the rat brain in vivo. Neuroscience 62:641-645.

Davila V, Yan Z, Craciun LC, Logothetis D, Sulzer D (2003) D3 dopamine autoreceptors do not activate G-protein-gated inwardly rectifying potassium channel currents in substantia nigra dopamine neurons. J Neurosci 23:5693-5697.

Floresco SB, West AR, Ash B, Moore H, Grace AA (2003) Afferent modulation of dopamine neuron firing differentially regulates tonic and phasic dopamine transmission. Nat Neurosci 6:968-973.

Ford CP, Mark GP, Williams JT (2006) Properties and opioid inhibition of mesolimbic dopamine neurons vary according to target location. J Neurosci 26:2788-2797.

Gaiarsa JL, Caillard O, Ben-Ari Y (2002) Long-term plasticity at GABAergic and glycinergic synapses: mechanisms and functional significance. Trends Neurosci 25:564-570.
Gainetdinov RR, Premont RT, Bohn LM, Lefkowitz RJ, Caron MG (2004) Desensitization of $\mathrm{G}$ protein-coupled receptors and neuronal functions. Annu Rev Neurosci 27:107-144.

Geffen LB, Jessell TM, Cuello AC, Iversen LL (1976) Release of dopamine from dendrites in rat substantia nigra. Nature 260:258-260.

Grace AA, Bunney BS (1984) The control of firing pattern in nigral dopamine neurons: burst firing. J Neurosci 4:2877-2890.

Grace AA, Onn SP (1989) Morphology and electrophysiological properties of immunocytochemically identified rat dopamine neurons recorded in vitro. J Neurosci 9:3463-3481.

Grillner P, Mercuri NB (2002) Intrinsic membrane properties and synaptic inputs regulating the firing activity of the dopamine neurons. Behav Brain Res 130:149-169.

Groves PM, Linder JC (1983) Dendro-dendritic synapses in substantia nigra: descriptions based on analysis of serial sections. Exp Brain Res 49:209-217.

Jaffe EH, Marty A, Schulte A, Chow RH (1998) Extrasynaptic vesicular transmitter release from the somata of substantia nigra neurons in rat midbrain slices. J Neurosci 18:3548-3553.

Jones S, Kornblum JL, Kauer JA (2000) Amphetamine blocks long-term synaptic depression in the ventral tegmental area. J Neurosci 20:5575-5580.

Kalivas PW, Duffy P (1991) A comparison of axonal and somatodendritic dopamine release using in vivo dialysis. J Neurochem 56:961-967.

Kohout TA, Lin FS, Perry SJ, Conner DA, Lefkowitz RJ (2001) $\beta$-Arrestin 1 and 2 differentially regulate heptahelical receptor signaling and trafficking. Proc Natl Acad Sci USA 98:1601-1606.

Koyrakh L, Lujan R, Colon J, Karschin C, Kurachi Y, Karschin A, Wickman K (2005) Molecular and cellular diversity of neuronal G-protein-gated potassium channels. J Neurosci 25:11468-11478.

Lacey MG, Mercuri NB, North RA (1987) Dopamine acts on D2 receptors to increase potassium conductance in neurones of the rat substantia nigra zona compacta. J Physiol (Lond) 392:397-416.

Lacey MG, Mercuri NB, North RA (1988) On the potassium conductance increase activated by GABAB and dopamine D2 receptors in rat substantia nigra neurones. J Physiol (Lond) 401:437-453.

Malenka RC, Bear MF (2004) LTP and LTD: an embarrassment of riches. Neuron 44:5-21.

Namkung Y, Sibley DR (2004) Protein kinase C mediates phosphorylation, desensitization, and trafficking of the D2 dopamine receptor. J Biol Chem 279:49533-49541.

Nirenberg MJ, Chan J, Liu Y, Edwards RH, Pickel VM (1996) Ultrastructural localization of the vesicular monoamine transporter-2 in midbrain dopaminergic neurons: potential sites for somatodendritic storage and release of dopamine. J Neurosci 16:4135-4145.

Park Y, Jo J, Isaac JT, Cho K (2006) Long-term depression of kainate receptor-mediated synaptic transmission. Neuron 49:95-106.

Phillips PE, Stuber GD, Heien ML, Wightman RM, Carelli RM (2003) Subsecond dopamine release promotes cocaine seeking. Nature 422:614-618.

Pucak ML, Grace AA (1994) Evidence that systemically administered dopamine antagonists activate dopamine neuron firing primarily by blockade of somatodendritic autoreceptors. J Pharmacol Exp Ther 271:1181-1192.

Rice ME, Cragg SJ, Greenfield SA (1997) Characteristics of electrically evoked somatodendritic dopamine release in substantia nigra and ventral tegmental area in vitro. J Neurophysiol 77:853-862.

Schultz W (2002) Getting formal with dopamine and reward. Neuron 36:241-263.

Taber MT, Das S, Fibiger HC (1995) Cortical regulation of subcortical dopamine release: mediation via the ventral tegmental area. J Neurochem 65:1407-1410.

Thomas MJ, Malenka RC (2003) Synaptic plasticity in the mesolimbic dopamine system. Philos Trans R Soc Lond B Biol Sci 358:815-819.

Thomas MJ, Malenka RC, Bonci A (2000) Modulation of long-term depression by dopamine in the mesolimbic system. J Neurosci 20:5581-5586.

Williams JT, North RA, Shefner SA, Nishi S, Egan TM (1984) Membrane properties of rat locus coeruleus neurones. Neuroscience 13:137-156.

Wilson CJ, Groves PM, Fifkova E (1977) Monoaminergic synapses, including dendro-dendritic synapses in the rat substantia nigra. Exp Brain Res 30:161-174. 